shown to contain an androgen receptor ligand (Table 1). However, the systematic study by Huang et al. reveals that a single compound found in both YZH and Yin Chin (6,7-dimethylesculetin) is sufficient to activate CAR and induce bilirubin clearance. This is a wonderful example of knowledge gained by applying the Western scientific method to an Eastern herbal remedy. It will be very exciting if a pure compound emerges from the tea leaves as a pharmacological therapy for neonatal jaundice that is complementary or alternative to the current Western practice of phototherapy (16).

1. Kinsella, K., and Gist, Y.J. 1998. Gender and Aging: Mortality and Health. U.S. Department of Commerce, U.S. Bureau of the Census. Washington, D.C. $1 \mathrm{~B} / 98-2$.

2. Carey, J. 2003. Herbal remedies: a \$4 billion enigma. BusinessWeek online, 28 April. http:// www.businessweek.com/magazine/content/ 03_17/b3830095_mz025.htm.

3. Huang, W., Zhang, J., and Moore, D.D. 2004. A traditional herbal medicine enhances bilirubin clearance by activating the nuclear receptor CAR. J. Clin. Invest. 113:137-143. doi:10.1172/JCI200418385.

4. Huang, W., et al. 2003. Induction of bilirubin clearance by the constitutive androstane receptor (CAR). Proc. Natl. Acad. Sci. U. S. A. 100:4156-4161.

5. Xie, W., et al. 2003. Control of steroid, heme, and carcinogen metabolism by nuclear pregnane $\mathrm{X}$ receptor and constitutive androstane receptor. Proc. Natl. Acad. Sci. U. S. A. 100:4150-4155.
6. Eisenberg, D.M. 1997. Advising patients who seek alternative medical therapies. Ann. Intern. Med. 127:61-69.

7. Chawla, A., Repa, J.J., Evans, R.M., and Mangelsdorf, D.J. 2001. Nuclear receptors and lipid physiology: opening the X-files. Science. 294:1866-1870.

8. Lazar, M.A. 2003. Mechanism of action of hormones that act on nuclear receptors. In William textbook of endocrinology. P.R. Larsen, H.M. Kronenberg, S. Melmed, and K.S. Polonsky, editors. W.B Saunders Co. Philadelphia, Pennsylvania, USA. 35-44.

9. Willson, T.M., and Moore, J.T. 2002. Genomics versus orphan nuclear receptors: a half-time report Mol. Endocrinol. 16:1135-1144.

10. Klinge, C.M., et al. 2003. Estrogenic activity in white and red wine extracts. J. Agric. Food Chem. 51:1850-1857.

11. Howitz, K.T., et al. 2003. Small molecule activators of sirtuins extend Saccharomyces cerevisiae lifespan. Nature. 425:191-196.

12. Etgen, G.J., et al. 2002. A tailored therapy for the metabolic syndrome: the dual peroxisome proliferator-activated receptor-alpha/gamma agonist LY465608 ameliorates insulin resistance and diabetic hyperglycemia while improving cardiovascular risk factors in preclinical models. Diabetes. 51:1083-1087.

13. Schwartz, T.B. 1999. Henry Harrower and the turbulent beginnings of endocrinology. Ann. Intern Med. 131:702-706.

14. Bhavnani, B.R. 2003. Estrogens and menopause: pharmacology of conjugated equine estrogens and their potential role in the prevention of neurodegenerative diseases such as Alzheimer's. J. Steroid Biochem. Mol. Biol. 85:473-482.

15. Stevenson, D.K., Wong, R.J., Hintz, S.R., and Vreman, H.J. 2002. The jaundiced newborn. Understanding and managing transitional hyperbilirubinemia. Minerva Pediatr. 54:373-382.

16. Dennery, P.A., Seidman, D.S., and Stevenson, D.K 2001. Neonatal hyperbilirubinemia. N. Engl. J. Med. 344:581-590.
17. Usui, T., et al. 2002. The phytochemical lindleyin, isolated from Rhei rhizoma, mediates hormonal effects through estrogen receptors. J. Endocrinol. 175:289-296.

18. Chan, R.Y., Chen, W.F., Dong, A., Guo, D., and Wong, M.S. 2002. Estrogen-like activity of ginsenoside Rg1 derived from Panax notoginseng. J. Clin. Endocrinol. Metab. 87:3691-3695.

19. Hsieh, T.C., Lu, X., Chea, J., and Wu, J.M. 2002. Prevention and management of prostate cancer using PC-SPES: a scientific perspective. J. Nutr. 132(Suppl.):3513S-3517S.

20. Zava, D.T., Dollbaum, C.M., and Blen, M. 1998 Estrogen and progestin bioactivity of foods, herbs, and spices. Proc. Soc. Exp. Biol. Med. 217:369-378.

21. Zhang, L.N., et al. 2000. Determination of vitamin D2 included with beta-cyclodextrin complex in "longmu zhuanggu chongji" by HPLC. Se Pu. 18:52-54.

22. Huang, M.E., et al. 1988. Use of all-trans retinoic acid in the treatment of acute promyelocytic leukemia. Blood. 72:567-572.

23. Urizar, N.L., et al. 2002. A natural product that lowers cholesterol as an antagonist ligand for FXR. Science. 296:1703-1706.

24. Jardat, M.S., Noonan, D.J., Wu, B., Avery, M.A., and Feller, D.R. 2002. Pseudolaric acid analogs as a new class of peroxisome proliferator-activated receptor agonists. Planta Med. 68:667-671.

25. Moore, L.B., et al. 2000. St. John's wort induces hepatic drug metabolism through activation of the pregnane X receptor. Proc. Natl. Acad. Sci. U. S. A 97:7500-7502.

26. Beck, V., Unterrieder, E., Krenn, L., Kubelka, W., and Jungbauer, A. 2003. Comparison of hormonal activity (estrogen, androgen and progestin) of standardized plant extracts for large scale use in hormone replacement therapy. J. Steroid Biochem. Mol. Biol. 84:259-268.

27. Takahashi, N., et al. 2002. Dual action of isoprenols from herbal medicines on both PPARgamma and PPARalpha in 3T3-L1 adipocytes and HepG2 hepatocytes. FEBS Lett. 514:315-322.

\title{
The relative roles of growth hormone and IGF-1 in controlling insulin sensitivity
}

\section{David R. Clemmons}

Department of Medicine, School of Medicine, University of North Carolina, Chapel Hill, North Carolina, USA

IGF-1 and growth hormone (GH) interact with insulin to modulate its control of carbohydrate metabolism. A new study (see the related article beginning on page 96) shows that blocking the effect of GH in the presence of low serum IGF-1 concentrations enhances insulin sensitivity.

J. Clin. Invest. 113:25-27 (2004). doi:10.1172/JCI200420660.

\footnotetext{
Address correspondence to: David R. Clemmons, Division of Endocrinology, Department of Medicine, University of North Carolina School of Medicine, CB 7170, Chapel Hill, North Carolina 27599, USA. Phone: (919) 966-4735;

Fax: (919) 966-6025;

E-mail: endo@medicineexch.med.unc.edu.

Conflict of interest: The author has declared that no conflict of interest exists.

Nonstandard abbreviations used: growth hormone $(\mathrm{GH})$.
}

Understanding the relative roles of peptide hormones in modulating responsiveness to insulin presents a major challenge because of the adaptability of the growth hormone/IGF-1/ insulin system. Changes in glucose and insulin secretion result in counter-regulatory responses, and modifications in growth hormone $(\mathrm{GH})$ and IGF-1 function alter insulin's ability to maintain normal carbohydrate homeostasis. Historically, this problem has been analyzed in both human and rodent hormone-deficiency models (e.g., GH deficiency) in which the hormone of interest is replaced and the metabolic consequences are determined (1). The recent development of tissue-selective knockout animal models has brought new insights to our understanding of the relative roles of these hormones in carbohydrate homeostasis. In this issue of the JCI, Yakar et al. address the relative roles of $\mathrm{GH}$ and IGF-1 in regulating insulin sensitivity in mice (2). The authors created an animal model in which IGF-1 synthesis in the liver is eliminated and then crossed these animals with mice that overexpress a mutant form of $\mathrm{GH}$ that prevents $\mathrm{GH}$ activation of its receptor. The authors conclude that $\mathrm{GH}$ is a major determinant of insulin resistance in these IGF-1-deficient animals, since, in the presence of low concentrations of serum IGF-1, blocking 


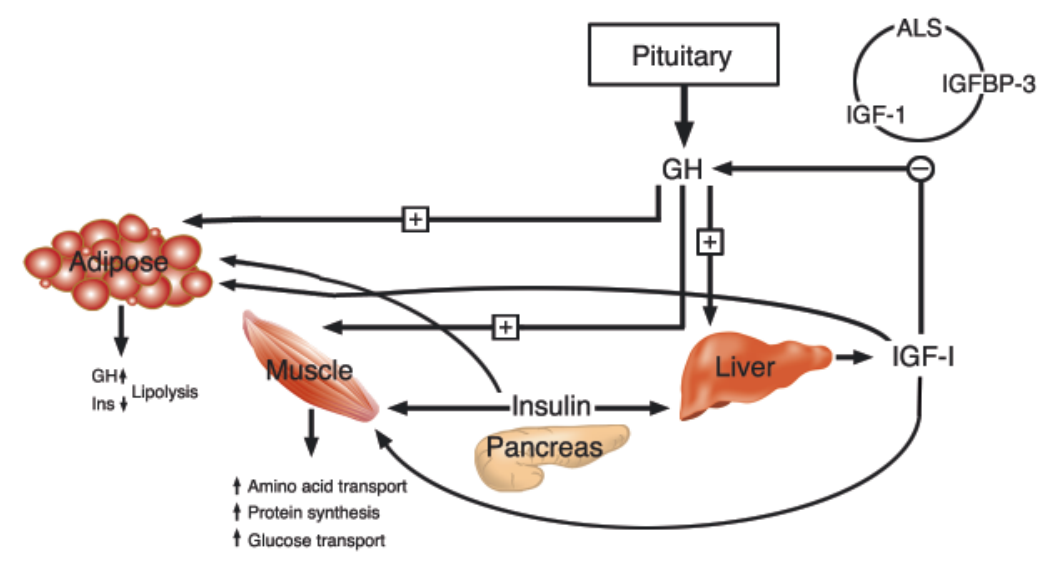

Figure 1

Schematic diagram of insulin, GH, and IGF-1 regulation. IGFBP-3, IGF-binding protein-3; ALS, acid-labile subunit.

the action of GH results in a major improvement in insulin sensitivity.

\section{Food intake and $\mathrm{GH}$ regulate insulin-like peptide secretion}

One way to understand the relative roles of IGF-1 in controlling insulin action is from the perspective of primitive organisms. In primitive organisms that do not have a pituitary gland, ligands with structural similarities to both insulin and IGF- 1 are synthesized in the olfactory region of the brain and secreted in response to food intake (3). This results in direct linking of food intake, carbohydrate metabolism, and growth, and a single receptor mediates these responses. In vertebrates, although IGF-1 secretion is primarily regulated by nutrient intake (4), GH secretion adds an additional layer of complexity (Figure 1). In higher organisms, $\mathrm{GH}$ controls growth by regulating IGF-1 concentrations, but another major function of GH is to provide a mechanism for surviving periods of food deprivation. GH stimulates lipolysis, providing FFAs and glycerol as substrates for energy metabolism, and also inhibits insulin-induced suppression of hepatic gluconeogenesis. These effects counteract insulin action and reduce the need for a dietary source of carbohydrate (5). An important distinction, however, is the relative role of GH in maintaining carbohydrate and lipid homeostasis under normal conditions as compared with conditions in which there is excess GH secretion (6). When $\mathrm{GH}$ is secreted in excess, it acts directly to block insulin signaling by inducing resistance to stimulation of downstream signaling molecules such as insulin receptor substrate- 1 and PI3K, which are important for glucose transport in muscle and fat and for inhibiting hepatic gluconeogenesis (7). This results in elevation of glucose and insulin concentrations. Thus patients with acromegaly often have impaired glucose intolerance and relative hyperinsulinemia (8). Similarly, in type 1 diabetes, insulin deficiency leads to impaired hepatic IGF-1 synthesis, and this results in decreased feedback suppression of GH secretion, leading to further impairment of insulin action (9). Administration of a GH antagonist to diabetics results in relative restoration of normal carbohydrate metabolism but does not completely ameliorate the defect in insulin sensitivity (10). Similarly, administration of a GH receptor antagonist to acromegalics improves insulin sensitivity but does not restore it to the normal range (11).

\section{Role of IGF-1 in modulating insulin sensitivity}

IGF-1, which has $48 \%$ amino acid sequence identity with proinsulin, enhances insulin sensitivity in both experimental animals and human subjects. IGF-1 binds to insulin receptors with very low affinity; therefore its binding to IGF-1 receptors and/or been postulated to be the mediator of enhanced insulin action (12). IGF-1 does not bind to hepatocytes or adipocytes, and therefore its primary hybrid insulin/IGF-1 receptors has insulin-sensitizing action is believed to be mediated through skeletal muscle. Administration of IGF-1 to normal humans results in glucose lowering that is approximately one-twelfth as potent as that induced by insulin (13), and in patients with extreme insulin resistance it improves insulin sensitivity and carbohydrate homeostasis (14).

One problem in interpreting almost all human studies of IGF-1 has been that, in addition to enhancing insulin action, it also suppresses GH secretion; therefore it has been difficult to determine the relative roles of the direct actions of IGF-1 and those that are mediated by suppression of GH. One exception is the group of individuals with $\mathrm{GH}$ receptor mutations who develop insulin resistance as adults. Administration of IGF-1 to these patients, who are unresponsive to $\mathrm{GH}$, results in improvement in insulin sensitivity (15, 16). This difficulty in distinguishing between the effects of GH suppression and the direct effects of IGF-1 has been addressed in the studies of Yakar et al. (2). In an earlier report, they showed that animals in which the liver-specific expression of the IGF-1 gene had been deleted had low serum IGF-1 and increased GH levels (17). These mice were hyperinsulinemic and resistant to insulin action in skeletal muscle. The authors extended those findings by overexpressing a dominant negative form of IGF-1 receptor in muscle. This resulted in attenuation of both IGF-1 and hybrid insulin/IGF-1 receptor function. These animals developed severe insulin resistance and diabetes (18). In contrast, deletion of the insulin receptor in muscle does not result in severe insulin resistance or diabetes (19). The authors interpreted the difference in the two models to be due to loss of IGF-1's sensitizing actions in skeletal muscle, leading to the development of insulin resistance.

Recently this group has further extended our understanding of this problem by creating a genetic model in which serum total IGF-1 concentrations are lowered by $85 \%$ but free IGF- 1 concentrations are increased (20). In this model, animals that do not express IGF-1 in the liver were crossed with animals that do not express the acid-labile subunit, a component of the IGF-1/ 
IGF-binding protein-3/acid-labile subunit complex in plasma, which functions to stabilize the half-life of IGF-1. In contrast to the animals with liver IGF-1 deletion, these animals showed enhanced insulin sensitivity in both adipose tissue and muscle but no change in liver. When these results are considered together with the current study (2), they suggest that the major site at which GH blocks insulin action is the liver. Although a secondary role for GH in skeletal muscle cannot be excluded, by this formulation, conditions that lead to increases in GH secretion (whether or not they are associated with lower serum IGF-1) may result in impaired hepatic insulin sensitivity, leading to decreased suppression of gluconeogenesis. Although GH no doubt has an insulin-counter-regulatory role in skeletal muscle, in that tissue the role of IGF-1 may be predominant. An additional issue is that overexpression of the $\mathrm{GH}$ antagonist completely eliminates GH action, and therefore this study does not definitively address the role of normal GH secretion and action in mediating insulin resistance. Thus future studies that use tissue-specific gene-deletion animal models and provide different levels of hormonereplacement therapy or that assess the effects of variable doses of the $\mathrm{GH}$ antagonist will be necessary to discern the relative roles of IGF-1 and GH in mediating insulin sensitivity in both normal physiologic and pathophysiologic states. Inhibiting $\mathrm{GH}$ action to attain a relatively normal physiologic level rather than a GH-deficient level will be necessary to further understand the contribution of IGF-1 in maintenance of normal glucose homeostasis in these models. Nevertheless, the studies of Yakar et al. highlight the importance of GH antagonism of insulin action in the liver and provide an important step in our understanding of the relative roles of each of these three hormones in maintaining this finely balanced mechanism.

1. Weaver, J.U., et al. 1995. The effect of low dose recombinant human growth hormone replacement on regional fat distribution, insulin sensitivity, and cardiovascular risk factors in hypopituitary adults. J. Clin. Endocrinol. Metab. 80:153-159.

2. Yakar, S., et al. 2004. Inhibition of growth hormone action improves insulin sensitivity in liver IGF-1-deficient mice. J. Clin. Invest. 113:96-105. doi:10.1172/JCI200417763.

3. Tatar, M., Bartke, A., and Antebi, A. 2003. The endocrine regulation of aging by insulin-like signals. Science. 299:1346-1351.

4. Isley, W.L., Underwood, L.E., and Clemmons, D.R. 1983. Dietary components that regulate serum somatomedin-C in humans. J. Clin. Invest. 71:175-182

5. Rizza, R.A., Mandarino, L.J., and Gerich, J.E. 1982. Effects of growth hormone on insulin action in man. Mechanisms of insulin resistance, impaired suppression of glucose production, and impaired stimulation of glucose utilization. Diabetes. 31:663-669

6. Holt, R.I., Simpson, H.L., and Sonksen, P.H. 2003 The role of growth hormone-insulin-like growth factor axis in glucose homeostasis. Diabet. Med. 20:3-15.

7. Dominici, F.P., Cifone, D., Bartke, A., and Turyn, D. 1999. Loss of sensitivity to insulin at early events of the insulin signaling pathway in the liver of growth hormone transgenic mice. J. Endocrinol. 161:383-392.

8. Ezzat, S., et al. 1994. Acromegaly: clinical and biochemical features 500 patients. Medicine. 73:233-240.

9. Edge, J.A., Dunger, D.B., Matthews, D.R., Gilbert,
J.P., and Smith, C.P. 1990. Increased overnight growth hormone concentrations in diabetic compared with normal adolescents. J. Clin. Endocrinol. Metab. 71:1356-1362.

10. Williams, R.M., et al. 2003. The effects of a specific growth hormone antagonist on overnight insulin requirements and insulin sensitivity in young adults with Type 1 diabetes mellitus. Diabetologia. 46:1203-1210.

11. O'Connell, T., and Clemmons, D.R. 2002. IGF-I/ IGFBP-3 combination improves insulin resistance by $\mathrm{GH}$ dependent and independent mechanisms. J. Clin. Endocrinol. Metab. 87:4356-4360.

12. Moses, A.C., Young, S.C.J., Morrow, L.A., O’Brien, M., and Clemmons, D.R. 1996. Recombinant human insulin-like growth factor I increases insulin sensitivity and improves glycemic control in type II diabetes. Diabetes. 45:91-100.

13. Guler, H.P., Zapf, J., and Froesch, E.R. 1987. Short-term metabolic effects of recombinant human insulin-like growth factor-I in healthy adults. N. Engl. J. Med. 317:137-140.

14. Morrow, L.A., O’Brien, M.B., Moller, D.E., Filer, J.S., and Moses, A.C. 1994. Recombinant human insulin-like growth factor-I therapy improves glycemic control and insulin action in the type A syndrome of severe insulin resistance. J. Clin. Endocrinol. Metab. 79:205-210.

15. Laron, Z. 1999. The essential role of IGF-I: lessons from the long-term study and treatment of children and adults with Laron syndrome. J. Clin. Endocrinol. Metab. 84:4397-4404.

16. Laron, Z., Avizur, Y., and Klinger, B. 1995. Carbohydrate metabolism in primary growth hormone resistance (Laron syndrome) before and during insulin-like growth factor-I treatment. Metabolism. 44:113-118.

17. Yakar, S., et al. 2001. Liver-specific IGF-1 gene deletion leads to muscle insulin insensitivity. Diabetes. 50:1110-1118.

18. Fernandez, A.M., et al. 2001. Functional inactivation of the IGF-I and insulin receptors in skeletal muscle causes type 2 diabetes. Genes Dev. 15:1926-1934.

19. Kim, J.K., et al. 2000. Redistribution of substrates to adipose tissue promotes obesity in mice with selective insulin resistance in muscle. J. Clin. Invest. 105:1791-1797.

20. Haluzik, M., et al. 2003. Insulin resistance in the liver-specific IGF-I gene-deleted mouse is abrogated by deletion of the acid-labile subunit of the IGF-binding protein-3 complex: relative roles of growth hormone and IGF-I in insulin resistance. Diabetes. 52:2483-2489. 